\title{
Effects of balance imagery of semi-tandem stance on a flat floor and balance beam for postural control: a comparison between older and younger adults
}

\author{
Jeong-Weon Lee ${ }^{a}$, Sujin Hwang ${ }^{b}$ \\ aDepartment of Occupational Therapy, Yeoju Institute of Technology, Yeoju, Republic of Korea \\ ${ }^{\mathrm{b}}$ Department of Physical Therapy, Division of Health Science, Baekseok University, Cheonan, Republic of Korea
}

Objective: Balance is a preceding task for functional activities in daily activities as well as community-dwelling activities. To learn skilled and functional activities, it is also necessary to imagine an appropriate and effective movement representation used to plan and execute the functional activities. The purpose of this study was to evaluate the effects of balance imagery of semi-tandem stance on a flat floor and balance beam on balance abilities for elderly and young adults.

Design: Cross-sectional study.

Methods: Fifteen elderly and thirty-four young adults were enrolled in this study. In order to determine whether there is a change in postural control ability according to the different imagery training methods used, standing static balance measurements were performed. According to the therapist's instructions, participants were to stand in a semi-tandem position on the Good Balance System for 1 minute while imagining that they were standing on a balance beam, and while the postural control abilities was assessed.

Results: Postural control was significantly different in balance ability of semi-tandem stance on a flat floor compared to on a balance beam in both geriatrics and young adults. Postural sway was more significantly decreased in young adults than older adults during balance imagery of semi-tandem stance on a flat floor as well as on balance beam $(p<0.05)$.

Conclusions: The results of this study suggest that the ability to mentally represent their actions was similar in older adults compared to young adults, although older adults showed a drop in efficiency of postural control more than young adults.

Key Words: Geriatrics, Imagery, Postural balance

\section{Introduction}

Approximately $30 \%$ of falls that occur among the elderly population leads to contusions, sprains, and fractures, which also leads to decreased active and voluntary movement [1]. Due to falls, this leads to decreased activities of daily living and functional activities and thus leading to decreased social and independence within the home. Therefore, falls can lead to decreased self-esteem, depression, and overall quality of life, and even lead to death. Death due to falling is considered the 7th most common cause of death amongst the elderly population [2].
One of the causes of falling among the elderly population is due to balance deficiency [3]. Balance is defined as the ability to maintain the center of mass (COM) within the base of support (BOS), or in other words, it is defined as postural stability. During the performance of activities of daily living, since the COM is displaced amongst the BOS, balance is perpetually challenged. Therefore, in order to prevent falls, the elderly population must be fully aware of the causes of falls and therapists must also develop fall prevention programs. Fall prevention programs include tai chi, aquatic training program, task-oriented approaches, strength training, and interactive computer programs [4-8].

Received: 12 November, 2015 Revised: 18 November, 2015 Accepted: 19 November, 2015

Corresponding author: Sujin Hwang

Department of Physical Therapy, Division of Health Science, Baekseok University, 76 Munam-ro, Dongnam-gu, Cheonan 31065 , Republic of Korea Tel: 82-41-550-2309 Fax: 82-41-550-2829 E-mail: sujin928@gmail.com

(c) This is an Open-Access article distributed under the terms of the Creative Commons Attribution Non-Commercial License (http://creativecommons.org/licens es/by-nc/4.0) which permits unrestricted non-commercial use, distribution, and reproduction in any medium, provided the original work is properly cited.

Copyright $@ 2015$ Korean Academy of Physical Therapy Rehabilitation Science 
Motor imagery practice is considered one of the many mental practices that are recently being used clinically. In order to activate skillful movements, planning and practice must take place, movement representation is an essential factor and is very effective [9]. Movement representation influences cognition and motor development and produces external reality and also is an internal forward model. Thus movement representation training facilitates image training [10]. There is evidence that motor imagery practice, although the movement cannot be seen visually, there is evidence of muscle activation, and is applied to music, sports, and CNS injured patients [11-14]. Within the clinic, training without movement is considered beneficial. Also, this can minimize the incidence of accidents due to lack of movement. It has been stated that when compared with a healthy adult, the mental ability an elderly adult is decreased and also has decreased expression abilities $[15,16]$.

Recently from one study, the order of finger movement within children and healthy subjects was explained, and after undergoing imagery training, the results showed that a difference in movement of the fingers. Coçola's study [17] included children, adult, and elderly subjects who were instructed on the order of finger movement. When compared with children and adults, the movement representation was similar among all the groups; however, the speed of finger movement was significantly decreased. However, although that it is been stated that motor imagery training produced positive results with elderly subjects, there are a lack of studies that have examined the effect of imagery motor training on gait and balance among the elderly population. Therefore, this study examined the effect of motor imagery training on balance in the young adult and elderly population.

The purpose of this study was to examine the effect of motor imagery training on the ability to maintain postural control while imagining being on a wide, flat wooden floor and on a narrow balance beam. The hypothesis was that imagery training of standing on a flat surface and a narrow surface would have an effect on balance in healthy adults. The second hypothesis was that there would be a difference in results between healthy adults and the elderly population post imagery training.

\section{Methods}

\section{Subjects}

This study included 15 elderly adults over the age of 65 (average age of 75 years) and 34 young adults (average age of 19.6 years). After the subjects have been informed about the purpose of the study and obtaining approval by the Institutional Research Board from Yeoju Institute of Technology, the subjects were able to participate in the study. The inclusion criteria for the subjects were as follows: (a) Have a Berg balance scale score of over 45 points; (b) Have an Activities-specific balance confidence scale score of over $66 \%$; (c) Had no experience of falls within the past 6 months; (d) Does not use an assistive devices during ambulation; (e) Able to maintain standing position with no presence of orthopedic or neurological diseases; and (f) Had not undergone balance or fall prevention training during the past 6 months. Table 1 shows the common characteristics of all the subjects in this study.

\section{Procedures}

This aim of this study was to observe for any differences amongst the young and elderly adults undergoing imagery training of standing in a semi-tandem position on a flat, wooden floor compared to a narrow, balance beam. In order to determine whether there is a change in postural control ability according to the different imagery training methods used, standing static balance measurements were performed. A platform of $80 \mathrm{~mm}$ in length, $100 \mathrm{~mm}$ in height was used with the standing semi-tandem position performed with the feet $15 \mathrm{~cm}$ apart. All subjects were instructed to imagine standing in two different surface conditions (wooden floor and a balance beam) while having their balance ability measured and were progressed to 7 levels as follows: (a) Level 1: Practice standing in a semi-tandem position on a flat, wooden floor for 1 minute; (b) Level 2: Sit on a chair and rest for 5 minutes; (c) Level 3: According to the therapist's instructions, subjects were to stand in a semi-tandem position on the Good Balance System for 1 minute while imagining that they are standing on flat, wooden floor.

Table 1. Baseline common and clinical characteristics of subjects

$(\mathrm{N}=49)$

\begin{tabular}{lcc}
\hline \multirow{2}{*}{ Variable } & \multicolumn{2}{c}{ Subject } \\
\cline { 2 - 3 } & $\begin{array}{c}\text { Geriatric adult } \\
(\mathrm{n}=15)\end{array}$ & $\begin{array}{c}\text { Young adult } \\
(\mathrm{n}=34)\end{array}$ \\
\hline Sex (male/female) & $4 / 11$ & $9 / 25$ \\
Age (y) & $75.0(6.4)$ & $19.6(1.9)$ \\
Height $(\mathrm{cm})$ & $156.3(4.4)$ & $165.7(8.2)$ \\
Weight $(\mathrm{kg})$ & $59.9(7.4)$ & $60.2(10.8)$ \\
\hline
\end{tabular}

Values are presented as number only or mean (SD). 
Balance ability was assessed; (d) Level 4: Sit on a chair and rest for 30 minutes; (e) Level 5: Practice standing in a semi-tandem position on a balance beam for 1 minute; (f) Level 6: Sit on a chair and rest for 5 minutes; and (g) Level 7: According to the therapist's instructions, subjects were to stand in a semi-tandem position on the Good Balance System for 1 minute while imagining that they are standing on a balance beam. Balance ability was assessed (Figure 1).

Subjects were instructed not to participate in any exercise programs and were only allowed to perform activities of daily living on the day of training. Also, the intake of alcohol and oral medications were limited. The subjects were instructed not to speak or move their head during the assessment. The therapists verbally read out loud the description of being on a flat, wooden floor and on narrow, balance beam to the subject.

In order to determine balance ability in this study, the mediolateral sway (ML), anterioposterior sway (AP), ML speed, AP speed, main axis, side of square (SQ), transverse sway distance (TSD), vertical sway distance (VSD), square of weight sway distance (SWSD) was assessed.

\section{Outcome measures}

\section{Static balance measurement device}

Static standing balance was assessed using the Good Balance System (Metitur Ltd., Jyvaskyla, Finland). The Good Balance System is a portable balance measuring device (force platform) that is light weight and triangular in form $(800 \times 800 \times$ $800 \mathrm{~mm}$ ), with a height of $110 \mathrm{~mm}$ and a digital operating system (MS Windows 2000 or higher; Microsoft, Redmond,
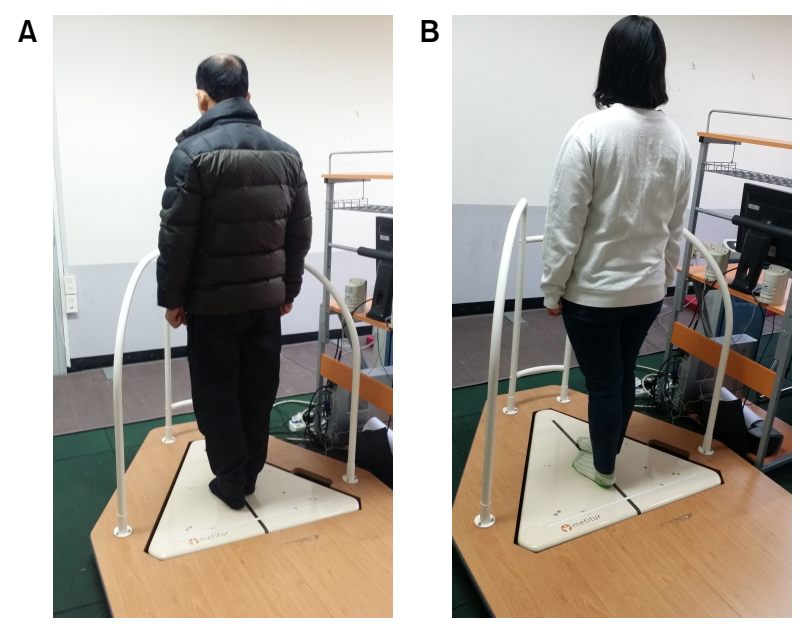

Figure 1. Experimental assessment of this study. (A) An elder participant in a semi-tandem standing. (B) A young participant in a semi-tandem standing
WA, USA). This device allows the assessment of real time measurement of the center of pressure (COP) sway and values, which are displayed on the monitor. The average COP values were measured in $\mathrm{mm} / \mathrm{s}$. Inside the forceplate is a transistor gauge. The analog signal from the gauge was passed from a 24 beat two-channel converter, producing a digital signal of $50 \mathrm{~Hz}$. The Good Balance System and the computer system was $10 \mathrm{~m}$ apart and wireless signals were exchanged through an external USB-Bluetooth and data was saved in a computer. The data was analyzed using the Good Balance 3.09 software (Metitur Ltd.) and the sampling rate was $50 \mathrm{~Hz}$ (Figure 2).

\section{Balance beam}

In order to perform the semi-tandem stand on a balance beam, a wooden balance beam (Balance Beam; Fumagalli, Ltd., Varase, Italy) was used. The beam was a $35 \mathrm{~cm}$ in length, $15 \mathrm{~cm}$ in width, and $11.5 \mathrm{~cm}$ in height, and is commonly used equipment within the clinic.

\section{Statistical analysis}

In order to analyze the general characteristics of the subjects, descriptive statistics was used, and the minimum, maximum, mean and standard deviation values were obtained. The independent variables were balance imagery training (flat floor) and balance beam, and the dependent variable was balance. The paired t-test was used to compare the imagery training of flat floor and balance beam in the young and geriatric adults. In order to compare the balance abilities of the young and geriatric adults in the imagery training of being on a flat floor and balance beam, an independent t-test was used. Data collection was analyzed using the PASW ver. 18.0 (IBM Co., Armonk, NY, USA), with a significant level set at $p<0.05$.

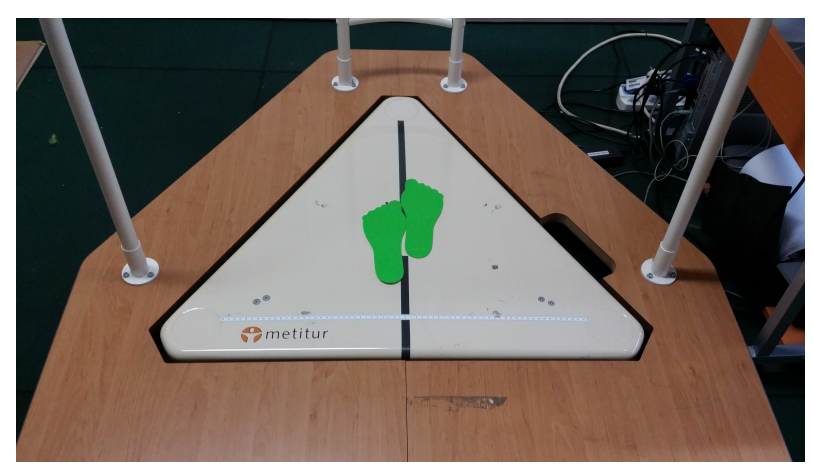

Figure 2. Static balance measure using Good Balance System. 
Table 2. Comparison of balance abilities on flat floor and balance beam in geriatric adults

$(\mathrm{N}=15)$

\begin{tabular}{|c|c|c|c|c|c|c|}
\hline \multirow{2}{*}{ Variable } & \multirow{2}{*}{ Flat floor } & \multirow{2}{*}{ Balance beam } & \multicolumn{2}{|c|}{$95 \%$ confidence interval } & \multirow{2}{*}{$\mathrm{t}$} & \multirow{2}{*}{$p$} \\
\hline & & & Lower bound & Upper bound & & \\
\hline $\operatorname{ML}(\mathrm{mm})$ & $28.5(20.9)$ & $32.8(21.0)$ & -10.7857 & 2.1590 & -1.429 & 0.175 \\
\hline $\mathrm{AP}(\mathrm{mm})$ & $153.2(32.6)$ & $140.1(31.3)$ & -10.4663 & 36.6530 & 1.192 & 0.253 \\
\hline ML speed $(\mathrm{mm} / \mathrm{s})$ & $8.7(5.0)$ & $11.5(5.4)$ & -4.2417 & -1.1850 & -3.808 & 0.002 \\
\hline AP speed (mm/s) & $8.9(2.9)$ & $11.6(3.9)$ & -4.3292 & -1.0975 & -3.601 & 0.003 \\
\hline $\mathrm{AX}$ & $74.3(56.6)$ & $66.8(61.3)$ & -45.4991 & 60.4324 & 0.302 & 0.767 \\
\hline $\mathrm{SQ}\left(\mathrm{mm}^{2}\right)$ & $18.5(4.8)$ & $22.3(6.1)$ & -6.0441 & -1.5292 & -3.598 & 0.003 \\
\hline TSD (mm) & $16.2(6.1)$ & $19.6(5.4)$ & -5.6303 & -1.0231 & -3.097 & 0.008 \\
\hline VSD (mm) & $14.0(3.6)$ & $17.2(6.9)$ & -6.8173 & 0.4840 & -1.860 & 0.084 \\
\hline $\operatorname{SWSD}\left(\mathrm{mm}^{2}\right)$ & $28.0(16.7)$ & $46.6(28.7)$ & -28.7988 & -8.4412 & -3.923 & 0.002 \\
\hline Score & $87.1(15.5)$ & $75.0(20.6)$ & 6.082 & 18.051 & 4.325 & 0.001 \\
\hline
\end{tabular}

Values are presented as mean (SD).

ML: mediolateral sway, AP: anterioposterior sway, ML speed: mediolateral sway speed, AP speed: anterioposterior sway speed, AX: main axis, SQ: side of square, TSD: transverse sway distance, VSD: vertical sway distance, SWSD: square of weight sway distance.

Table 3. Comparison of balance abilities on flat floor and balance beam in healthy young adults

$(\mathrm{N}=34)$

\begin{tabular}{lcccccc}
\hline \multirow{2}{*}{ Variable } & Flat floor & Balance beam & \multicolumn{2}{c}{$95 \%$ confidence interval } & t & $p$ \\
\cline { 4 - 5 } & & & Lower bound & Upper bound & & \\
\hline ML $(\mathrm{mm})$ & $84.7(44.9)$ & $149.6(118.8)$ & -102.3659 & -27.5635 & -3.534 & 0.001 \\
AP $(\mathrm{mm})$ & $142.9(53.0)$ & $168.9(73.9)$ & -14.6251 & -10.4161 & -3.393 & 0.002 \\
ML speed $(\mathrm{mm} / \mathrm{s})$ & $4.2(2.2)$ & $7.5(5.9)$ & -5.1199 & -1.3801 & -3.536 & 0.001 \\
AP speed $(\mathrm{mm} / \mathrm{s})$ & $7.1(2.6)$ & $8.5(3.7)$ & -2.0981 & -0.5372 & -3.435 & 0.002 \\
AX & $92.6(22.3)$ & $96.2(39.1)$ & -21.0662 & 13.8309 & -0.422 & 0.676 \\
SQ $\left(\mathrm{mm}^{2}\right)$ & $15.6(6.6)$ & $22.6(13.7)$ & -11.3271 & -2.8435 & -3.398 & 0.002 \\
TSD $\left(\mathrm{mm}^{2}\right)$ & $8.1(4.2)$ & $16.0(13.9)$ & -11.9246 & -3.7225 & -3.881 & $<0.001$ \\
VSD $(\mathrm{mm})$ & $15.3(6.6)$ & $19.7(10.4)$ & -8.0877 & -0.6770 & -2.406 & 0.022 \\
SWSD $\left(\mathrm{mm}^{2}\right)$ & $13.9(12.2)$ & $33.2(39.5)$ & -31.6855 & -6.9851 & -3.185 & 0.003 \\
Score & $70.2(24.9)$ & $45.7(28.8)$ & 15.736 & 33.323 & 5.675 & $<0.001$ \\
\hline
\end{tabular}

Values are presented as mean (SD).

ML: mediolateral sway, AP: anterioposterior sway, ML speed: mediolateral sway speed, AP speed: anterioposterior sway speed, AX: main axis, SQ: side of square, TSD: transverse sway distance, VSD: vertical sway distance, SWSD: square of weight sway distance.

\section{Results}

Within the geriatric adults, there was a statistically significant increase in ML speed, AP speed, SQ, TSD, and SWSD when doing imagery training of standing on a balance beam compared to being on a flat floor (Table 2). There was no statistically significant difference in the ML, AP, AX, and VSD. Within the young adults, there was a statistically significant increase in ML, AP, ML speed, AP speed, SQ, TSD, VSD, SWSD, except for AX when doing imagery training of standing on a balance beam compared to a flat floor (Table 3). Within the young adults, there was a statistically significant increase in ML and AX, and a significant decrease in ML speed during the flat floor imagery training condition (Table 4). During imagination on standing on a balance beam, there was a statistically significant increase in ML, AP, AX, and SQ values within the young adult population compared to the geriatric population (Table 5).

\section{Discussion}

This study compared the postural control abilities among elderly and young adults while standing in a semi-tandem position and undergoing imagery training by imagining on standing on a flat, wooden floor and a balance beam. The results of study were as follows. First, when comparing the condition of undergoing imagery training while standing in semi-tandem position on a flat floor versus a balance beam 
Table 4. Balance abilities on flat floor between geriatric adults and healthy young adults

$(\mathrm{N}=49)$

\begin{tabular}{|c|c|c|c|c|c|c|}
\hline \multirow{2}{*}{ Variable } & \multirow{2}{*}{$\begin{array}{l}\text { Geriatric adult } \\
\qquad(\mathrm{n}=15)\end{array}$} & \multirow{2}{*}{$\begin{array}{l}\text { Young adult } \\
\quad(\mathrm{n}=34)\end{array}$} & \multicolumn{2}{|c|}{$95 \%$ confidence interval } & \multirow{2}{*}{$\mathrm{t}$} & \multirow{2}{*}{$p$} \\
\hline & & & Lower bound & Upper bound & & \\
\hline ML (mm) & $28.5(20.9)$ & $84.7(44.9)$ & 31.68867 & 80.71486 & 4.612 & 0.017 \\
\hline $\mathrm{AP}(\mathrm{mm})$ & $153.2(32.6)$ & $142.9(53.0)$ & -40.18371 & 19.46410 & -.699 & 0.210 \\
\hline ML speed $(\mathrm{mm} / \mathrm{s})$ & $8.7(5.0)$ & $4.2(2.2)$ & -6.57133 & -2.44554 & -4.397 & 0.005 \\
\hline AP speed $(\mathrm{mm} / \mathrm{s})$ & $8.9(2.9)$ & $7.1(2.6)$ & -3.44544 & -0.03221 & -2.050 & 0.454 \\
\hline $\mathrm{AX}$ & $74.3(56.6)$ & $92.6(22.3)$ & -4.21638 & 40.79128 & 1.635 & $<0.001$ \\
\hline $\mathrm{SQ}\left(\mathrm{mm}^{2}\right)$ & $18.5(4.8)$ & $15.6(6.6)$ & -6.75321 & 0.90223 & -1.538 & 0.398 \\
\hline TSD (mm) & $16.2(6.1)$ & $8.1(4.2)$ & -11.11604 & -5.10082 & -5.424 & 0.057 \\
\hline VSD (mm) & $14.0(3.6)$ & $15.3(6.6)$ & -2.36769 & 4.96181 & 0.712 & 0.096 \\
\hline $\operatorname{SWSD}\left(\mathrm{mm}^{2}\right)$ & $28.0(16.7)$ & $13.9(12.2)$ & -22.66144 & -5.57974 & -3.326 & 0.199 \\
\hline Score & $87.1(15.5)$ & $70.2(24.9)$ & -30.85912 & -2.80362 & -2.414 & 0.015 \\
\hline
\end{tabular}

Values are presented as mean (SD).

ML: mediolateral sway, AP: anterioposterior sway, ML speed: mediolateral sway speed, AP speed: anterioposterior sway speed, AX: main axis, SQ: side of square, TSD: transverse sway distance, VSD: vertical sway distance, SWSD: square of weight sway distance.

Table 5. Balance abilities on balance beam between geriatric adults and healthy young adults

$(\mathrm{N}=49)$

\begin{tabular}{|c|c|c|c|c|c|c|}
\hline \multirow{2}{*}{ Variable } & \multirow{2}{*}{$\begin{array}{l}\text { Geriatric adult } \\
\qquad(\mathrm{n}=15)\end{array}$} & \multirow{2}{*}{$\begin{array}{l}\text { Young adult } \\
\quad(n=34)\end{array}$} & \multicolumn{2}{|c|}{$95 \%$ confidence interval } & \multirow{2}{*}{$\mathrm{t}$} & \multirow{2}{*}{$p$} \\
\hline & & & Lower bound & Upper bound & & \\
\hline ML (mm) & $32.8(21.0)$ & $149.6(118.8)$ & 54.34758 & 179.35870 & 3.761 & 0.025 \\
\hline $\mathrm{AP}(\mathrm{mm})$ & $140.1(31.3)$ & $168.9(73.9)$ & -11.30788 & 68.81611 & 1.444 & 0.018 \\
\hline ML speed $(\mathrm{mm} / \mathrm{s})$ & $11.5(5.4)$ & $7.5(5.9)$ & -7.57606 & -0.36747 & -2.217 & 0.572 \\
\hline AP speed $(\mathrm{mm} / \mathrm{s})$ & $11.6(3.9)$ & $8.5(3.7)$ & -5.47147 & -0.79755 & -2.698 & 0.842 \\
\hline $\mathrm{AX}$ & $66.8(61.3)$ & $96.2(39.1)$ & 0.16412 & 58.57941 & 2.023 & 0.028 \\
\hline $\mathrm{SQ}\left(\mathrm{mm}^{2}\right)$ & $22.3(6.1)$ & $22.6(13.7)$ & -7.10409 & 7.85037 & 0.100 & 0.040 \\
\hline TSD (mm) & $19.6(5.4)$ & $16.0(13.9)$ & -11.10286 & 3.87972 & -0.970 & 0.128 \\
\hline VSD (mm) & $17.2(6.9)$ & $19.7(10.4)$ & -3.40046 & 8.42595 & 0.855 & 0.055 \\
\hline $\operatorname{SWSD}\left(\mathrm{mm}^{2}\right)$ & $46.6(28.7)$ & $33.2(39.5)$ & -36.25802 & 9.44743 & -2.414 & 0.819 \\
\hline Score & $75.0(20.6)$ & $45.7(28.8)$ & -45.89397 & -12.69427 & -3.550 & 0.006 \\
\hline
\end{tabular}

Values are presented as mean (SD).

ML: mediolateral sway, AP: anterioposterior sway, ML speed: mediolateral sway speed, AP speed: anterioposterior sway speed, AX: main axis, SQ: side of square, TSD: transverse sway distance, VSD: vertical sway distance, SWSD: square of weight sway distance.

among the geriatric adults, there was a significant difference in ML speed, AP speed, main axis, SQ, TSD, VSD, and SWSD. Second, when comparing the condition of undergoing imagery training while standing in a semi-tandem position on a balance beam versus on a flat floor in the young adults, there was a significant difference in ML speed, AP speed, main axis, SQ, TSD, VSD, and SWSD. Third, when comparing the balance control abilities between the geriatric and young adult population while undergoing the two conditions of imagery training in a semi-tandem standing position, there was a significant increase in mediolateral and displacement of main axis, and a significant decrease in ML speed among the young adults. Finally, when comparing the balance control abilities between the geriatric and young adult population while undergoing the two conditions of imagery training in a semi-tandem standing position, there was a significant difference in the ML speed, AP speed, main axis, SQ within the young adults.

As stated in the introduction, death within the elderly population due to unintentional injuries has been 5 th in rank along with cardiovascular being the first, malignancy being second, stroke ranking third and lung disease ranking fourth, and $2 / 3$ of deaths through unintentional injuries are due to falls [18]. Also, of all the adults 65 years or older within the community, over $33 \%$ experience a fall annually. Elderly adults with experience of falls, or even those who have not experienced a fall before, most commonly experience a fall when walking on a busy street, walking while talking to a 
friend or moving a fragile object (dual tasks) [19,20]. Therefore, in order for the elderly population to be able to carry out functional activities of daily living, having appropriate postural control can be considered as an important factor, and postural control-related rehabilitation strategies are needed [21]. This study was to investigate the effects of imagery training on postural control in elderly adults. In case of the elderly adults, after having them practice standing in a semi-tandem foot position on a flat floor for one minute, they were asked to stand on the force plate and imagine themselves being on a flat surface while standing in a semi-tandem standing position. They were also asked to practice standing in a semi-tandem foot position on a balance beam for 1 minute, and then imagine themselves being on a balance beam while standing in a semi-tandem foot position on the force plate. When comparing these two situations, there was a significant increase in the $\mathrm{ML}$ and $\mathrm{AP}$ speed. In addition, when doing imagery training of standing on a flat surface in a semi-tandem position compared to a balance beam, there was a significant increase of ML distance and SQ during balance beam imagery training. The results were similar in the young adults. For the young adults, there was a significant increase in ML distance, ML speed, AP, AP distance, and AP speed when undergoing imagery training of standing on a balance beam while standing in a semi-tandem foot position on a force plate compared to when doing imagery training of standing on a flat floor in a semitandem position. Among the young and elderly adults, there was a difference in postural control abilities according to the imagery training task, and the exercise imagining abilities among the elderly adults were similar to young adults.

This study compared the postural control abilities between young and elderly adults. In the elderly adults, the ML, ML speed, AX, etc. all showed a significant increase while performing a semi-tandem standing position on the force plate while undergoing imagery training of standing on a balance beam in a similar standing position. Also, in the ML, AP, main axis and sway distance, there was a statistical significant increase. These results showed that there was no difference in the ability to do imagery training among the young and elderly adults, but the fact is, the functional activity level of the body within the elderly adults has been decreased. To generalize, the results can be analyzed that the use of imagery training for balance can affect the postural control abilities, although, in the elderly adults, the functional activities are carried out, the physical abilities may decrease; however, there was no difference in the movement during imagery training. Therefore, when doing postural control training among the elderly adults, this could prevent injuries while performing physical training, for elderly adults who cannot maintain their standing balance, an exercise program using imagery training could be used for the purpose of increasing the elderly adults' abilities to perform postural control.

This study was not a repetitive training program, but instead was to investigate the immediate effects of imagery training on postural control. Further studies warrant the need to include an exercise program similar to this, and also investigate the changes in the elderly adults performing the exercise program. This study was to investigate the effects of performing imagery training on a flat surface and a balance beam on postural control among the elderly and young adults. These results showed that when doing imagery training of standing in a semi-tandem foot position (on a force plate) versus a flat floor, there was a significant increase in the movement of the COM, which appeared in both the young and elderly adults. However, when comparing the elderly adults to the young adults, of all the conditions, there were two conditions that showed a decrease. Based on the results, although the physical abilities to perform postural control may have been decreased, the elderly adults showed a similar ability to do imagery training as young adults. The results showed that the ability to undergo imagery training was similar. However, through the imagery training, secondary injury can be dramatically decreased, and the study results are supportive of planning a fall prevention program being implemented.

\section{Conflict of Interest}

The authors declared no potential conflicts of interest with respect to the authorship and/or publication of this article.

\section{References}

1. Painter JA, Elliott SJ, Hudson S. Falls in community-dwelling adults aged 50 years and older: prevalence and contributing factors. J Allied Health 2009;38:201-7.

2. Shumway-Cook A, Woollacott MH. Motor control: translating research into clinical practice. 4th ed. Philadelphia: Wolters Kluwer Health/Lippincott Williams \& Wilkins; 2010.

3. Peeters G, van Schoor NM, Lips P. Fall risk: the clinical relevance of falls and how to integrate fall risk with fracture risk. Best Pract Res Clin Rheumatol 2009;23:797-804.

4. Boisgontier MP, Beets IA, Duysens J, Nieuwboer A, Krampe RT, 
Swinnen SP. Age-related differences in attentional cost associated with postural dual tasks: increased recruitment of generic cognitive resources in older adults. Neurosci Biobehav Rev 2013;37:1824-37.

5. Kruse RL, Lemaster JW, Madsen RW. Fall and balance outcomes after an intervention to promote leg strength, balance, and walking in people with diabetic peripheral neuropathy: "feet first" randomized controlled trial. Phys Ther 2010;90:1568-79.

6. Li F, Harmer P, Stock R, Fitzgerald K, Stevens J, Gladieux M, et al. Implementing an evidence-based fall prevention program in an outpatient clinical setting. J Am Geriatr Soc 2013;61:2142-9.

7. Szturm T, Betker AL, Moussavi Z, Desai A, Goodman V. Effects of an interactive computer game exercise regimen on balance impairment in frail community-dwelling older adults: a randomized controlled trial. Phys Ther 2011;91:1449-62.

8. Yadegaripour M, Sadeghi H, Shojaedin SS, Shamsehkohan P. Effects of a combined aquatic-nonaquatic training program on static and dynamic balance in elderly men. J Am Geriatr Soc 2013;61:1417-9.

9. Caeyenberghs K, Tsoupas J, Wilson PH, Smits-Engelsman BC. Motor imagery development in primary school children. Dev Neuropsychol 2009;34:103-21.

10. Molina M, Tijus C, Jouen F. The emergence of motor imagery in children. J Exp Child Psychol 2008;99:196-209.

11. Brown RM, Palmer C. Auditory and motor imagery modulate learning in music performance. Front Hum Neurosci 2013;7: 320.

12. Guillot A, Desliens S, Rouyer C, Rogowski I. Motor imagery and tennis serve performance: the external focus efficacy. J Sports Sci Med 2013;12:332-8
13. Kho AY, Liu KP, Chung RC. Meta-analysis on the effect of mental imagery on motor recovery of the hemiplegic upper extremity function. Aust Occup Ther J 2014;61:38-48.

14. Kingsley JD, Zakrajsek RA, Nesser TW, Gage MJ. The effect of motor imagery and static stretching on anaerobic performance in trained cyclists. J Strength Cond Res 2013;27:265-9.

15. Mulder T, Hochstenbach JB, van Heuvelen MJ, den Otter AR. Motor imagery: the relation between age and imagery capacity. Hum Mov Sci 2007;26:203-11.

16. Personnier P, Ballay Y, Papaxanthis C. Mentally represented motor actions in normal aging: III. Electromyographic features of imagined arm movements. Behav Brain Res 2010;206:184-91.

17. Caçola P, Roberson J, Gabbard C. Aging in movement representations for sequential finger movements: a comparison between young-, middle-aged, and older adults. Brain Cogn 2013; $82: 1-5$.

18. Kojima G. Frailty as a predictor of future falls among communitydwelling older people: a systematic review and meta-analysis. J Am Med Dir Assoc 2015;16:1027-33.

19. Plummer-D'Amato P, Cohen Z, Daee NA, Lawson SE, Lizotte MR, Padilla A. Effects of once weekly dual-task training in older adults: a pilot randomized controlled trial. Geriatr Gerontol Int 2012;12:622-9.

20. Menant JC, Schoene D, Sarofim M, Lord SR. Single and dual task tests of gait speed are equivalent in the prediction of falls in older people: a systematic review and meta-analysis. Ageing Res Rev 2014;16:83-104.

21. Rubenstein LZ. Falls in older people: epidemiology, risk factors and strategies for prevention. Age Ageing 2006;35 Suppl 2:ii37ii41. 